\title{
Caracterização do perfil vertical do dossel de um trecho de Mata Atlântica através de escaneamento laser aerotransportado
}

\author{
Canopy vertical profile characterization of a stretch \\ of Atlantic Forest using airborne laser scanning
}

\author{
Tiago de Conto', Eric Bastos Görgens², André Gracioso Peres da Silva3, \\ Danitiele Cristina França Laranja ${ }^{4}$ e Luiz Carlos Estraviz Rodriguez ${ }^{5}$
}

\begin{abstract}
Resumo
A busca de camadas verticais homogêneas no dossel de uma floresta pode facilitar estudos para que inferências mais precisas sobre a estrutura de complexos agrupamentos arbóreos possam ser obtidas. $O$ objetivo deste trabalho foi caracterizar o perfil vertical do dossel florestal em uma área de floresta ombrófila densa (bioma Mata Atlântica) a partir de um levantamento laser aerotransportado (ALS - Airborne Laser Scanning). Com o apoio da análise de agrupamento hierárquico, foram concatenadas classes de altura de um metro que resultaram em oito estratos de mínima colinearidade entre classes. Para essas classes de altura, o método k-means indicou que células de grade regular que cobria toda a área de estudo poderiam ser reunidas em quatro grupos de perfil vertical: baixo (pontos ALS entre 7 e 11 metros), médio-baixo (pontos ALS entre 15 e 18 metros), médio-alto (pontos ALS entre 19 e 22 metros) e alto (pontos ALS entre 23 e 26 metros). Esses grupos refletem características do perfil vertical do dossel em escala de ecosítio, evidenciando diferenças estruturais da paisagem. Os grupos obtidos apresentaram distribuição espacial coerente com a topografia local, além de correspondência com levantamentos ecológicos anteriormente conduzidos em campo por outros autores.
\end{abstract}

Palavras-chave: LiDAR, estratificação vertical, ALS, análise de agrupamento, nuvem de pontos.

\begin{abstract}
The search for relatively homogeneous vertical layers in the canopy of a forest can facilitate studies so that inferences about the ecosystem structure of complex arboreal groups can be obtained more accurately. The objective of this study was to characterize the vertical profile of the forest canopy in an area of dense rain forest ("Mata Atlântica" biome) by means of an ALS (Airborne Laser Scanning) assessment. Supported by a hierarchical cluster analysis, we considered classes of one meter height that ended up grouped in eight strata with minimum co-linearity among classes. Among these height classes, the k-means method indicated that the cells of the regular grid covering the entire study area could be clustered into four groups of vertical profile: low (ALS points between 7 and 11 meters), medium-low (ALS points between 15 and 18 meters), medium-high (ALS points between 19 and 22 meters) and high (ALS points between 23 and 26 meters). These groups reflect characteristics of the vertical profile of the canopy at the study scale, as well as structural differences in the landscape. The obtained groups showed coherent spatial distribution to the local topography and correspondence to ecological surveys previously conducted in the field by other authors.
\end{abstract}

Keywords: LiDAR, vertical stratification, ALS, cluster analysis, point cloud.

\footnotetext{
${ }^{1}$ Mestrando em Manejo Florestal. SLU - Swedish University of Agricultural Sciences, Southern Swedish Forest Research Centre - Sundsvägen 3, SE-230 53 Alnarp, Sweden. E-mail: tdc.florestal@gmail.com

2Professor e Pesquisador do Departamento de Engenharia Florestal. UFVJM - Universidade Federal dos Vales do Jequitinhonha e Mucuri. Campus JK - Rod. MGT 367, Km 583, 5000 - Alto do Jacuba - 39100-000 - Diamantina, MG. E-mail: gorgens@usp.br

${ }^{3}$ Mestre em Recursos Florestais. USP - Universidade de São Paulo - ESALQ - Escola Superior de Agricultura "Luiz de Queiroz". Av. Pádua Dias, 11 - 13418-900 - Piracicaba, SP - E-mail: andregracioso@gmail.com

${ }^{4}$ Mestrando(a) em Recursos Florestais. USP - Universidade de São Paulo - Departamento de Ciências Florestais / ESALQ - Escola Superior de Agricultura "Luiz de Queiroz". Av. Pádua Dias, 11 - 13418-900 - Piracicaba, SP. E-mail: danitiele.cfl@gmail.com

${ }^{5}$ Professor Associado do Departamento de Engenharia Florestais. USP - Universidade de São Paulo - ESALQ - Escola Superior de Agricultura "Luiz de Queiroz". Av. Pádua Dias, 11 - 13418-900 - Piracicaba, SP. E-mail: lcer@usp.br
}

Sci. For., Piracicaba, v. 43, n. 108, p. 873-884, dez. 2015 DOI: dx.doi.org/10.18671/scifor.v43n108.12 


\section{INTRODUÇÃO}

A classificação ecológica de espaços é fundamental e estratégica no manejo da biodiversidade em ecossistemas tropicais. DeGraaf e Miller (1996) adotam a seguinte classificação hierarquizada de espaços para diferentes escalas cartográficas: ecozona (> 1:5.000.000); ecorregião (até 1:1.000.000); ecodistrito (até 1:125.000); ecoseção (1:250.000 a 1:50.000); ecosítio (1:50.000 a 1:10.000); e ecoelemento (1:10.000 a 1:2.500).

Sabendo-se da grande variabilidade natural das florestas tropicais, sua subdivisão em partições homogêneas que apresentem características ecológicas similares funciona no sentido de representar a estrutura ecossistêmica altamente complexa dessas áreas, permitindo inferências mais acuradas (FELFILI et al. 2011). Nesse sentido, a caracterização vertical do dossel em estratos pode oferecer elementos que explicam parte dessa biodiversidade.

Levantamentos ecológicos ao nível de paisagem são onerosos, de alto custo e baixa eficiência. Áreas de florestas naturais geralmente apresentam grande extensão territorial, e especialmente no caso do bioma Mata Atlântica, seus maiores remanescentes encontram-se associados a áreas de difícil acesso, como encostas e topos de morro (EISENLOHR et al., 2011). Assim, a obtenção de informações florestais a partir de delineamentos amostrais tradicionais baseados em levantamentos de campo exige grande quantidade de recursos humanos e financeiros.

A adoção de novas tecnologias para a coleta de informações de forma contínua (no tempo e espaço) das florestas naturais é uma alternativa para contornar esse problema, daí o grande interesse pelas técnicas de sensoriamento remoto, aplicadas aos levantamentos florestais atualmente (HILKER et al., 2008; TOMPPO et al., 2008). Dentre as técnicas de sensoriamento remoto, os levantamentos baseados no escaneamento laser aerotransportado (ALS - Airborne Laser Scanning) vêm se destacando pela capacidade de gerar informações tridimensionais com alta resolução (WHITE et al., 2013). Diversas aplicações da tecnologia ALS já se consolidaram no cenário florestal internacional, como: levantamento de biomassa (DRAKE et al., 2003), mensuração do índice de área foliar (RIAÑO et al., 2004), inventário e manejo florestal (McROBERTS et al., 2012; ZONETE et al., 2010).

Essa tecnologia abre novas possibilidades no estudo da estrutura vertical de áreas florestais, que usualmente adota estratos em intervalos de altura arbitrários, por conta da baixa precisão e intensidade amostral tipicamente adotada nos inventários convencionais em florestas naturais (LATHAM et al., 1998). O levantamento contínuo tridimensional por ALS gera dados abundantes, contrastando com os métodos convencionais de levantamento de campo, baseados em parcelas ou faixas. Morsdorf et al. (2010) fizeram a estratificação vertical de uma floresta mediterrânea a partir de dados de altura e intensidade de retornos ALS, identificando três estratos. Os autores encontraram correlações variando de 0,73 a 0,96 entre perfis verticais derivados do LiDAR (Light Detection and Ranging) e perfis baseados em mensurações de campo.

O bioma Mata Atlântica abriga uma das mais altas diversidades biológicas nos trópicos (JOLY et al.,1991), diversidade esta que tem sido relacionada à grande variedade de habitats dentro de sua área de ocorrência (BROWN; BROWN, 1992). Diferentes habitats permitem o estabelecimento de diferentes comunidades arbóreas, e o padrão de estratificação vertical pode ser utilizado como indicador do tipo de fitofisionomia e do estágio de sucessão dessas comunidades (LANA et al., 2010).

O acesso às tecnologias de mapeamento 3D permite aferir à questão do zoneamento ambiental/ ecológico por um novo ângulo. Sensores LiDAR são capazes de capturar pequenas variações no perfil vertical de paisagens florestadas. Utilizando-se técnicas apropriadas para a filtragem e tratamento da nuvem de pontos, torna-se possível o seu particionamento e inferência direta sobre a estrutura vertical da vegetação através do perfil vertical de dossel. Esse consiste na distribuição de frequências de retornos por intervalo de altura e servem como indicativo da quantidade de biomassa por estrato de altura (SILVA et al., 2015).

O presente estudo tem por objetivo caracterizar o perfil vertical de dossel e fazer a estratificação horizontal em escala de ecosítio de uma área de floresta ombrófila densa (bioma Mata Atlântica), com base apenas em similaridades na distribuição de pontos na nuvem LiDAR, obtida por levantamento laser aerotransportado. 


\section{MATERIAL E MÉTODOS}

\section{Área de estudo}

A área de estudo (Figura 1) está incluída no Parque Estadual da Serra do Mar, Núcleo Santa Virgínia (coordenadas entre $23^{\circ} 17^{\prime}-23^{\circ} 24^{\prime} \mathrm{S}$ e $45^{\circ} 03^{\prime}-45^{\circ} 11^{\prime} \mathrm{W}$ ), inserida em uma estreita faixa do Planalto Atlântico entre a região costeira e o Vale do Paraíba, abrangendo os municípios paulistas de São Luiz do Paraitinga e Natividade da Serra (IF, 2006).

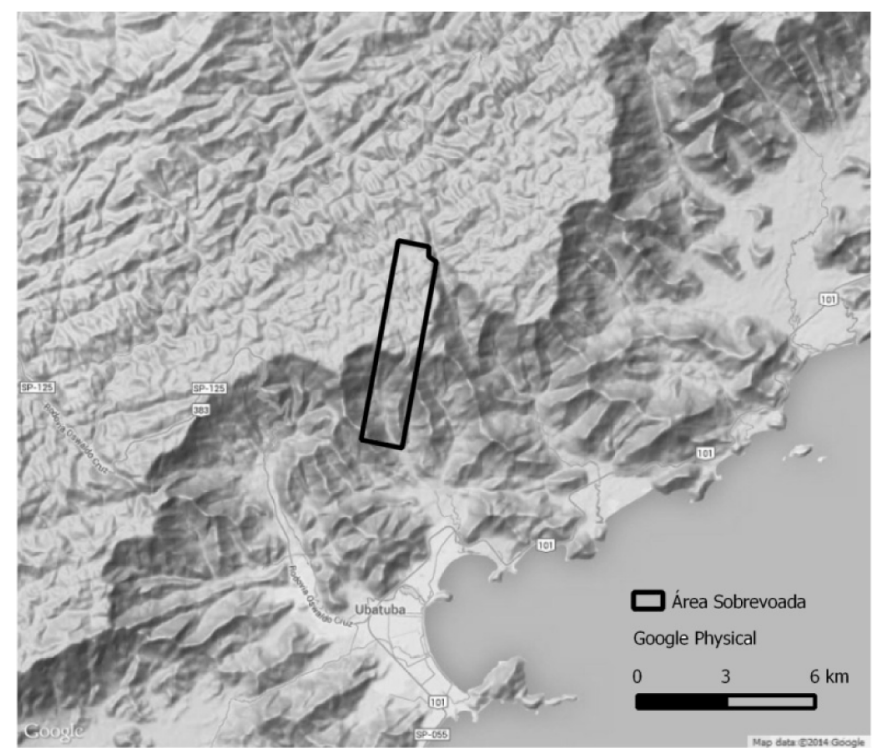

Figura 1. Localização da área de estudo no Parque Estadual da Serra do Mar, próximo à cidade de Ubatuba - SP. Figure 1. Study area at "Serra do Mar" State Park near Ubatuba - SP.

Segundo Medeiros (2009), pela classificação de Köppen o clima da região é do tipo Cwa, com precipitação média anual de $2.180 \mathrm{~mm}$, sendo dezembro, janeiro e fevereiro os meses mais úmidos, e junho, julho e agosto os de menor pluviosidade. Todos os meses possuem precipitação média superior a $60 \mathrm{~mm}$. A vegetação predominante, de acordo com o sistema de classificação de Veloso et al. (1991), é do tipo Floresta Ombrófila Densa Montana.

A floresta ombrófila densa é caracterizada pela presença de fanerófitos, lianas lenhosas e epífitos em abundância. Sua característica ecológica principal está relacionada diretamente às elevadas temperaturas (média de $25^{\circ} \mathrm{C}$ ) e à praticamente ausência de período seco, devido às chuvas bem distribuídas ao longo do ano. Os solos predominantes pertencem à classe dos LATOSSOLOS, e em alguns casos CAMBISOLOS, ambos de baixa fertilidade natural. Destacam-se os ecótipos do gênero Ficus, Alchornea, Tabebuia e Calophyllum. A área sobrevoada faz parte do bioma brasileiro Mata Atlântica.

\section{Levantamento ALS}

Os dados são provenientes de um sobrevoo LiDAR, financiado pelo projeto Paisagens Sustentáveis (parceria EMBRAPA e Serviço Florestal Norte-americano), sobre uma área de $9.49 \mathrm{~km}^{2}$ num gradiente altitudinal no Parque Estadual da Serra do Mar, em setembro de 2009. Os parâmetros do voo estão disponíveis na Tabela 1.

A nuvem LiDAR foi normalizada utilizando o modelo digital de terreno (MDT) com pixels de um metro (Figura 2). O MDT foi gerado pelo prestador de serviço GEOID Ltda., utilizando o software TerraScan, com as seguintes características: exatidão absoluta horizontal inferior a 0.5 metros para áreas planas e 0.75 metros nas áreas de inclinação superior a 20\%; exatidão absoluta vertical inferior a $0.15 \mathrm{~m}$ nas áreas planas e a 0.5 metros nas áreas com declividade maior que 20\%; exatidão horizontal relativa entre faixas inferior a 0.3 metros e exatidão vertical relativa entre faixas inferior a $0.15 \mathrm{~m}$. 
Conto et al. - Caracterização do perfil vertical do dossel de um trecho

de Mata Atlântica através de escaneamento laser aerotransportado

Tabela 1. Parâmetros do levantamento laser aerotransportado.

Table 1. Airborne laser scanning survey parameters.

\begin{tabular}{lc}
\hline Parâmetro & Valor \\
\hline Área total sobrevoada & 1170,31 ha \\
Altura de voo & 1.500 metros \\
Sensor LiDAR & ALTM 3100 \\
Frequência de emissão de pulso & $50 \mathrm{kHz}$ \\
Ângulo de escaneamento & $10^{\circ}$ \\
Frequência de escaneamento & $25 \mathrm{~Hz}$ \\
Sobreposição de faixas & $30 \%$ \\
Densidade média de retornos & $22 \mathrm{pts}^{\circ} \mathrm{m}^{2}$ \\
\hline
\end{tabular}

Estabeleceu-se uma grade regular sobre a nuvem LiDAR normalizada (com alturas relativas ao chão, e não ao nível médio dos mares) com células de um hectare (100 x $100 \mathrm{~m})$ e orientação norte-sul $\left(0^{\circ}\right)$. Para cada célula da grade foi obtida a quantidade absoluta de retornos por classe de altura, em intervalos de um metro (Figura 2), resultando numa matriz de 1035 linhas (células da grade) e 51 colunas (classes de altura em que existiram retornos, 0 a 50 metros). O intervalo de 0 a 1 metro de altura foi desconsiderado por incluir retornos provenientes do terreno.
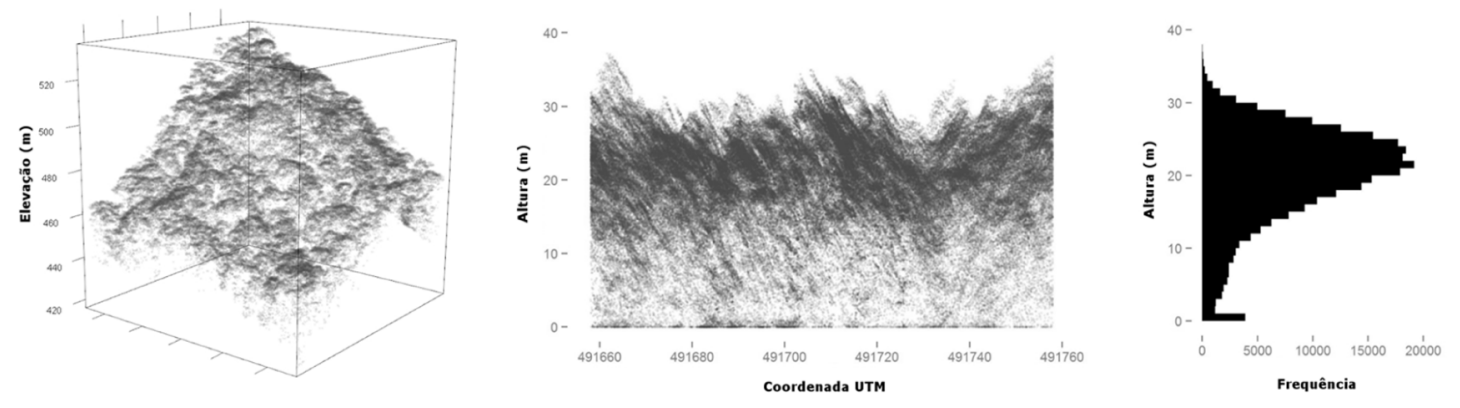

Figura 2. Sequência de geração do perfil vertical de dossel. Da esquerda para a direita: nuvem de pontos em 3D; nuvem normalizada em 2D; perfil vertical do dossel (frequência de retornos por intervalos de um metro de altura).

Figure 2. Process to generate the canopy height profile. From left to right: 3D point cloud; 2D normalized cloud; canopy height profile (frequency of returns per height class).

\section{Processamento e análise dos dados.}

Os valores por classe de altura foram relativizados pela quantidade total de retornos em cada célula da grade regular (Equação 1). A relativização dos dados elimina os efeitos da variabilidade da quantidade absoluta de retornos, que é influenciada por fatores como velocidade da aeronave no momento da coleta de dados e sobreposição das faixas escaneadas.

$$
\mathrm{p}_{\mathrm{n}_{\mathrm{q}}}=\frac{\mathrm{n}_{\mathrm{ij}}}{\mathrm{N}_{\mathrm{j}}}
$$

onde:

$\mathrm{p}_{\mathrm{nij}}=$ proporção de pontos ALS na classe de altura $i$, na célula $j$ da grade regular; $\mathrm{n}_{\mathrm{ij}}=$ número bsoluto de pontos ALS levantados na classe de altura $i$, na célula $j$ da grade regular; $\mathrm{N}_{\mathrm{j}}=\sum_{i=1}^{51} n_{j}=$ total absoluto de pontos ALS retornados, para todas as classes de altura, na célula $j$ da grade regular.

As classes de altura em intervalos de um metro foram submetidas à análise de agrupamento hierárquico (métodos do vizinho mais próximo, distância média e do vizinho mais distante - single, average e complete linkage) para identificar a possibilidade de união de classes colineares e consequente redução de redundância. A métrica de distância adotada foi a euclidiana, por sua simplicidade e versatilidade (PASCUAL et al., 2008). 
O algoritmo de agrupamento escolhido foi aquele com maior correlação cofenética, resultante do cálculo da correlação de Pearson entre os valores da matriz de distâncias originais, calculadas para todos os possíveis pares de observações, e a matriz de distâncias obtida a partir do dendrograma (distâncias cofenéticas) após realização do agrupamento.

Com base nas novas classes de perfil vertical de dossel, realizou-se um agrupamento não hierárquico das células da grade, pelo método k-means. As variáveis de entrada foram as classes de altura propostas pelo agrupamento hierárquico. A determinação do número de grupos a serem formados pelo k-means foi feita a partir de uma abordagem iterativa, buscando obter a estabilização da variabilidade interna a cada grupo no patamar mínimo. O número de grupos foi então validado através de uma análise de componentes principais (ACP).

Por fim foi gerada uma malha matricial (raster) da área, com cada pixel correspondendo a uma célula da grade regular, identificando espacialmente os grupos obtidos pela análise de agrupamentos k-means. O agrupamento foi analisado por interpretação visual da imagem gerada e pela associação com trabalhos de campo publicados na literatura sobre a mesma área de estudo. Na análise visual, buscou-se considerar a distribuição espacial dos grupos, bem como sua distribuição considerando o relevo e a rede hidrográfica.

\section{RESULTADOS}

O método de agrupamento hierárquico adotado foi o do vizinho mais distante (complete linka$g e)$, por apresentar maior correlação cofenética $(0,89)$ entre a matriz de distâncias original e pós-agrupamento. Esse método indicou um agrupamento de classes de altura em intervalos variáveis, porém sequenciais (Figura 3 ).

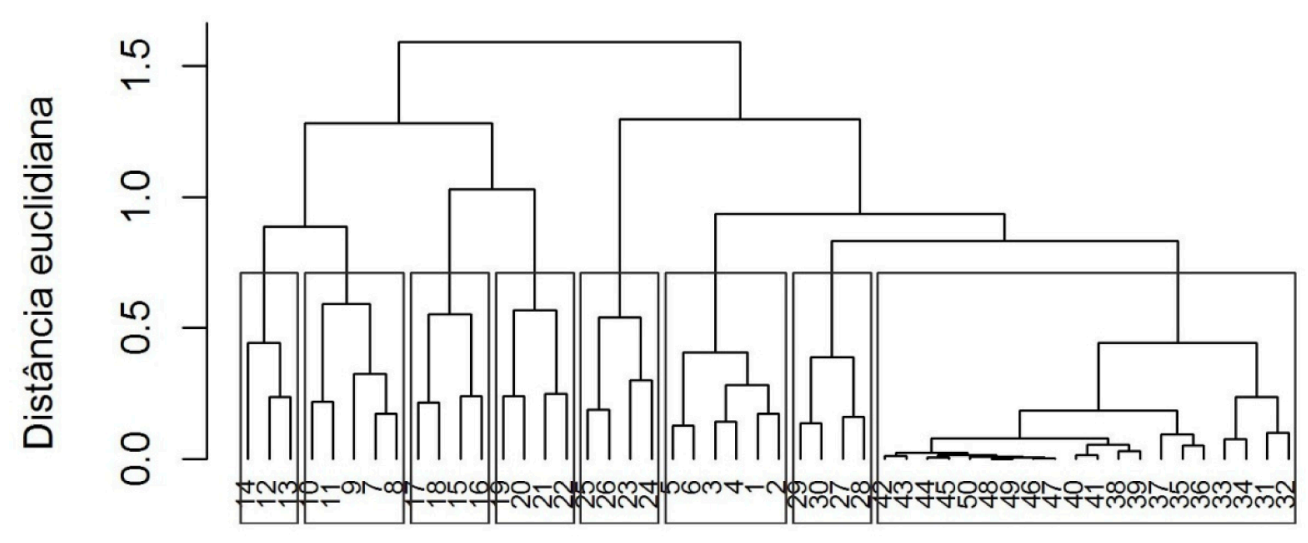

\section{Classes de altura $(\mathrm{m})$}

Figura 3. Dendrograma de agrupamento hierárquico pelo método do vizinho mais distante. Os 50 intervalos de altura foram agrupados em oito estratos homogêneos.

Figure 3. Hierarchical clustering dendrogram for the complete linkage method. The 50 height intervals were grouped into eight homogeneous strata.

Pelo corte adotado do dendrograma foram formados oito grupos para a construção dos estratos verticais (1-6.9 m, 7-11.9 m, 12-14.9 m, 15-18.9 m, 19-22.9 m, 23-26.9 m, 27-30.9 m, 31-50 m). As médias por estrato vertical para a área toda constam na Figura 4. 
Conto et al. - Caracterização do perfil vertical do dossel de um trecho

de Mata Atlântica através de escaneamento laser aerotransportado

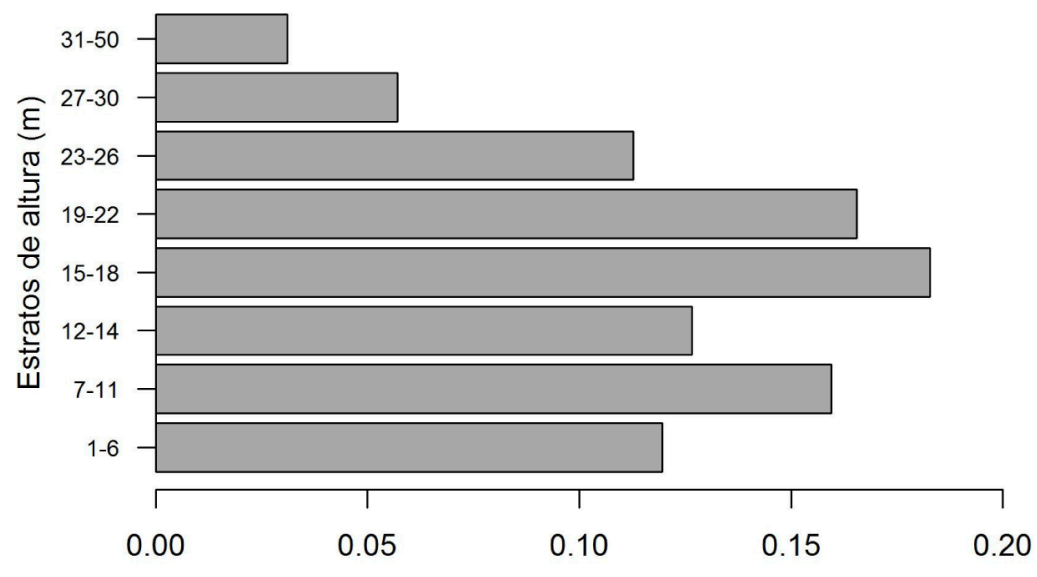

Percentual médio de pontos coletados

Figura 4. Proporção média de retornos por estrato de altura para toda a área de estudo.

Figure 4. Mean proportion of returns per height stratum for the entire study area.

A seleção do número de grupos para agrupamento das observações pelo método $k$-means foi feita por meio de simulações com número crescente de grupos. A qualidade do agrupamento foi avaliada pela soma de quadrados interna aos grupos e pelo coeficiente de determinação $\left(\mathrm{R}^{2}\right)$, conforme Figura 5.

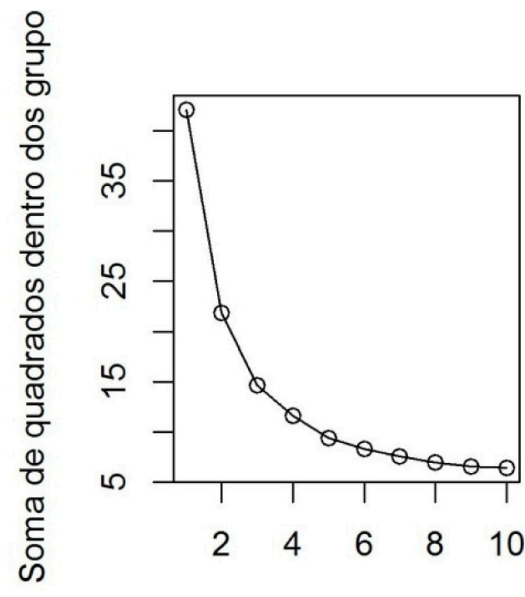

Número de grupos

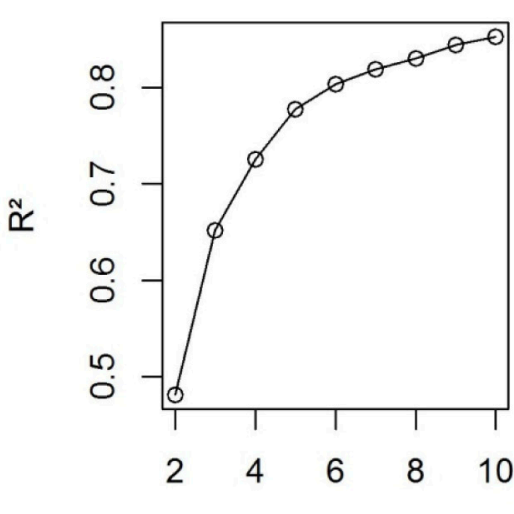

Número de grupos

Figura 5. Estatísticas de avaliação geradas para as simulações de agrupamento k-means com número de grupos crescentes.

Figure 5. Statistics of performance generated for k-means simulations with increasing group numbers.

Foram adotados quatro grupos, como indicado pelo ponto de curvatura máxima na Figura 5, em que o acréscimo de grupos após o quarto não diminuiu a variabilidade interna aos grupos de forma substancial. A ACP permitiu identificar as relações entre estratos de altura e grupos obtidos pelo k-means (Figura 6). 


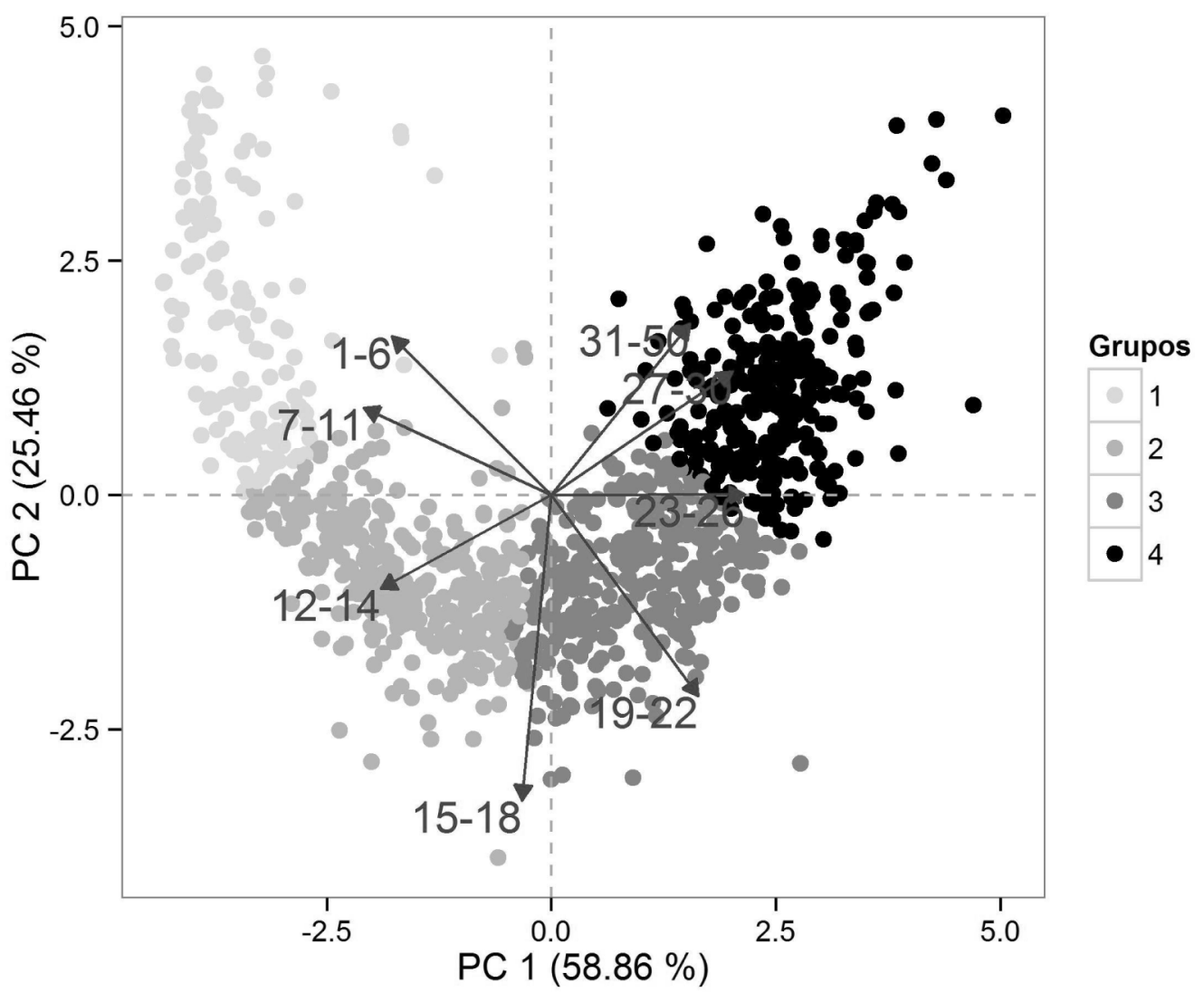

Figura 6. Biplot dos dois primeiros componentes da Análise de Componentes Principais. Estratos verticais estão representados por vetores saindo da origem e células da grade regular estão representadas por pontos.

Figure 6. Biplot of the first two components of the Principal Component Analysis. Vertical strata are represented by vectors starting from the origin and regular grid cells are represented by points.

A ACP baseou-se na matriz de correlações dos dados agrupados. Os dois primeiros componentes apresentaram uma variância acumulada de $84,31 \%$. A Tabela 2 apresenta os autovetores e autovalores associados aos mesmos. A partir do terceiro componente, os autovalores absolutos foram inferiores à unidade, não sendo utilizados na interpretação dos resultados.

Tabela 2. Autovetores e autovalores associados aos dois primeiros componentes da ACP.

Table 2. Eigenvectors and eigenvalues associated with the first two PCA components.

\begin{tabular}{lcc}
\hline Estratos verticais $(\mathbf{m})$ & Primeiro autovetor & Segundo autovetor \\
\hline $1-6$ & $-0,35$ & 0,34 \\
$7-11$ & $-0,42$ & 0,19 \\
$12-14$ & $-0,38$ & $-0,20$ \\
$15-18$ & $-0,07$ & $-0,65$ \\
$19-22$ & 0,33 & $-0,43$ \\
$23-26$ & 0,43 & 0,00 \\
$27-30$ & 0,41 & 0,26 \\
$31-50$ & 0,31 & 0,36 \\
Autovalor & 4,71 & 2,04 \\
\hline
\end{tabular}

O autovetor associado ao primeiro componente apresentou pesos bem distribuídos para todos os estratos verticais, com exceção do estrato de 15-18 metros, que apresentou menor peso para o primeiro autovetor, porém maior peso para o segundo autovetor.

A Figura 7 apresenta a distribuição dos escores ao longo desses componentes, ordenados de acordo com seus respectivos grupos. Rotulamos o primeiro componente de "gradiente vertical", devido à projeção dos escores nesse eixo apresentar um padrão linear e crescente, indo do grupo mais fortemente associado aos retornos de alturas baixas até o grupo com maiores percentuais de retornos nos estratos mais altos, de forma ordenada. 

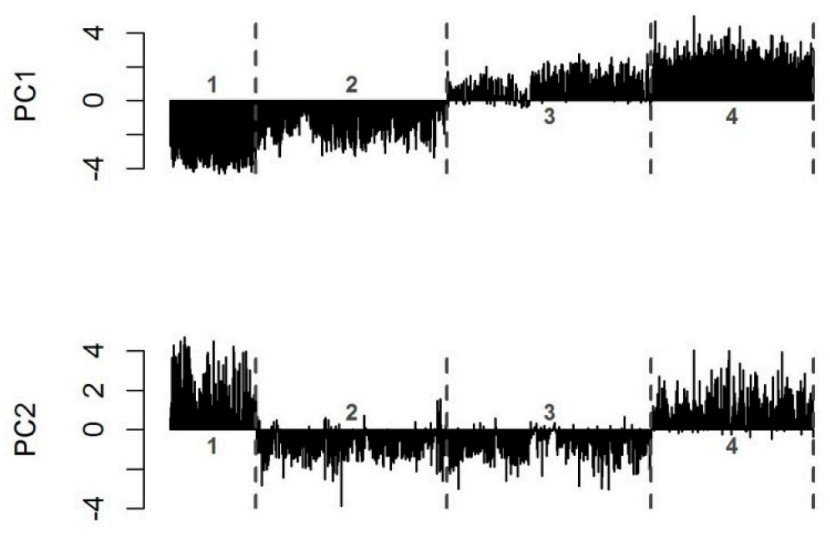

Grupos

Figura 7. Escores ordenados por grupo para os dois primeiros componentes da ACP. Figure 7. Sequence of scores by group for the first two PCA components.

O segundo componente foi denominado "gradiente de densidade", por apresentar escores fortemente associados aos estratos verticais intermediários e com maiores quantidades de retornos. Esses estratos intermediários concentram-se na metade negativa do componente, enquanto escores associados aos estratos extremos (alturas mais altas e mais baixas) e com menor quantidade de retornos concentram-se na metade positiva. Os grupos de 1 a 4 foram nomeados, respectivamente: perfil baixo, médio-baixo, médio-alto e alto (Figura 8).
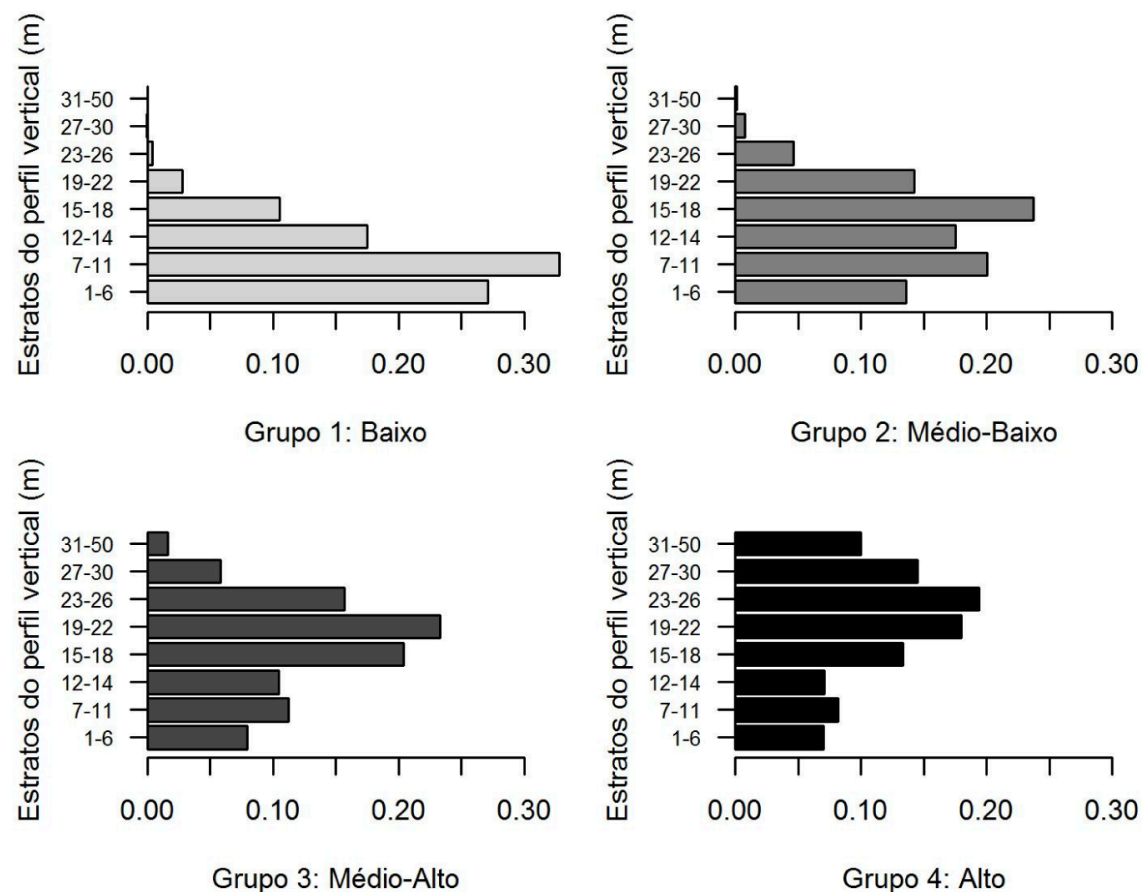

Figura 8. Estratos do perfil vertical dentro de cada grupo, rotulados respectivamente como baixo, médio-baixo, médio-alto e alto.

Figure 8. Strata of the vertical profile within each group, labeled respectively as low, medium-low, medium-high and high.

Observa-se na Figura 9 que a distribuição espacial dos grupos acompanha variações no relevo. $\mathrm{O}$ grupo 4 (perfil alto) apresenta-se bem distribuído nas áreas de menor elevação ao sul, intercalado pelo grupo 3 (perfil médio-alto). A metade norte apresenta maiores altitudes e menor oscilação do relevo. O grupo 1 (perfil baixo) apresenta-se em manchas associadas a áreas de baixada nessa porção, enquanto o grupo 3 associa-se às feições mais altas. O grupo 2 (perfil médio-baixo) apresenta-se bem distribuído por toda a metade norte, envolvendo os grupos 1 e 3. 


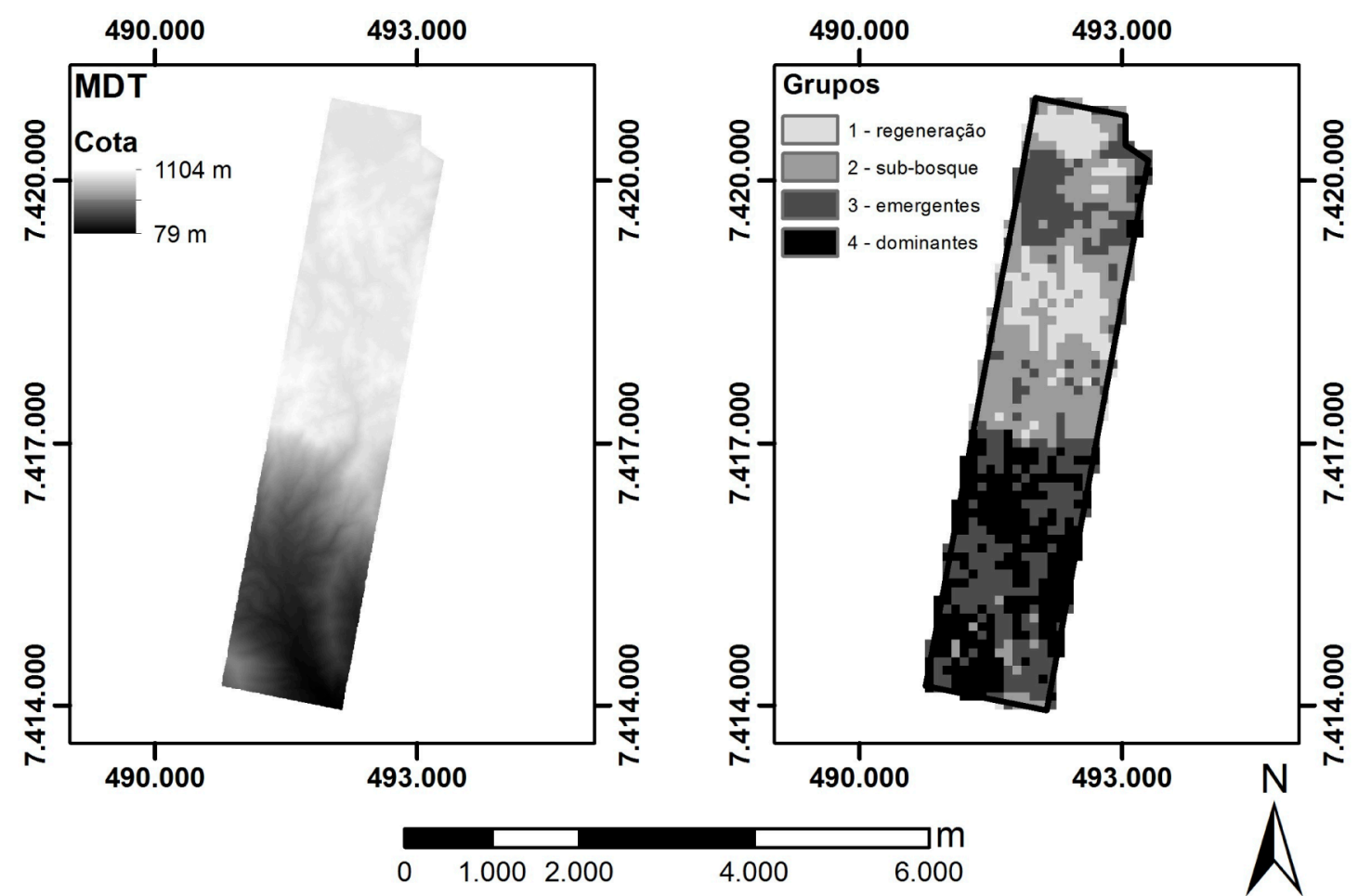

Figura 9. Modelo digital do terreno (MDT) e mapa de alocação dos grupos em SIRGAS 2000, coordenadas UTM, zona 23S.

Figure 9. Digital terrain model (MDT) and grouping information map in SIRGAS 2000, UTM coordinates, zone 235.

Nota-se a correspondência entre a formação dos grupos e a topografia local, visto que grupos extremos (perfis alto e baixo) não se conectam diretamente, sendo intercalados pelos grupos com perfis verticais intermediários. Ressalta-se a expressão do gradiente de densidade, visto que os grupos 1 e 4 ocupam menor proporção da área (13,4\% e 25,2\%, respectivamente), quando contrastados aos grupos 2 e 3, que ocupam $29,7 \%$ e 31,7\% da área, respectivamente.

\section{DISCUSSÃO}

Trabalhos botânicos já evidenciaram a existência de diferenças estruturais dentro dessas áreas de floresta ombrófila densa. Gomes et al. (2011), em estudo também no Parque Estadual da Serra do Mar, indicaram a existência de dois grupos em diferentes níveis altitudinais. A 350 metros de altitude, foram observados mais indivíduos, maior riqueza e maior volume do que na base da encosta $(190 \mathrm{~m})$. O agrupamento baseado no perfil vertical de dossel também indicou a presença de dois grupos nessas altitudes (grupo médio-alto e alto). Sabendo-se da correlação entre produção primária e altura, os resultados obtidos por análise da nuvem de pontos LiDAR corroboram com os de Gomes et al. (2011).

Medeiros (2009) encontrou num trabalho também realizado no núcleo Santa Virgínia, do Parque Estadual da Serra do Mar, 13 fitofisionomias por meio de fotointerpretação. Dessas, nove foram agrupadas na classe de formação denominada Floresta Ombrófila Densa Montana, e quatro foram agrupadas na classe de formação denominada Floresta Ombrófila Densa Aluvial, que se caracterizam como formações associadas a corpos d'água ou localizadas em áreas inundáveis. $\mathrm{O}$ autor ainda descreve que as áreas aluviais apresentaram porte arbóreo variável, desde alto, caracterizando as matas ripárias, passando por médio em planícies restritas, até porte arbóreo baixo, nas planícies sujeitas a inundação periódica. Nesta última classe de formação, também foi incluída uma fisionomia de porte herbáceo, que corresponde às formações aluviais das áreas localizadas em planícies de inundação em terrenos encharcados.

Parte das áreas estudadas por Medeiros (2009) estão contempladas na metade norte da área de estudo (Figura 9), em elevações superiores a mil metros. As áreas aluviais colocalizaram-se ao grupo de perfil vertical de dossel baixo (extremo norte - Figura 9), enquanto que áreas com predominância de porte arbóreo alto, com dossel homogêneo colocalizaram-se ao grupo de perfil vertical de 
dossel médio-alto (noroeste - Figura 9). Áreas identificadas por Medeiros (2009) com predominância de vegetação de porte arbóreo médio/alto, com dossel desuniforme e manchas de taquaras e bambus colocalizaram-se à área de perfis verticais de dossel médio-baixo e baixo.

Lacerda (2001) indica a distribuição de três principais comunidades arbóreas ao longo do gradiente altitudinal do Parque, composto por floresta de planície (próximo ao nível do mar), floresta de meia-encosta (100 - 600 metros) e floresta de alto do morro (1000 metros). O autor encontrou maior diversidade e riqueza de espécies em áreas com elevação de 300 metros. Diferenças na estrutura da vegetação tornaram-se mais evidentes a partir de 600 metros, com mudança abrupta na sua estrutura e composição a partir dos 1000 metros. No seu estudo, os indivíduos mais altos e robustos encontraram-se entre 100 e 300 metros $\left(0,7 \mathrm{~m}^{3} /\right.$ indivíduo), enquanto áreas em cotas acima de 1000 metros apresentaram indivíduos mais baixos e finos $\left(0,5 \mathrm{~m}^{3} /\right.$ indivíduo $)$. A quantidade de indivíduos arbóreos com mais de 25 metros de altura decresceu com aumento da altitude (100, 300 e 600 metros), não havendo registros desses indivíduos aos mil metros. Houve ainda redução da área basal e aumento da densidade de indivíduos com a elevação. As diferenças fitossociológicas entre as cotas do parque devem-se, principalmente, a fatores edáficos. Segundo Martins (2010), as áreas mais férteis do parque se encontram entre 150 e 400 metros de altitude.

Os grupos encontrados com base no perfil vertical de dossel apresentaram notáveis correspondências com o trabalho de Lacerda (2001), tais como: a mudança abrupta na estrutura da floresta a partir dos mil metros de altitude, maiores valores de altura nos ecosítios de encosta, perfis verticais mais baixos acima dos mil metros, separação espacial entre os grupos baixo e médio-baixo (na encosta) e médio-alto e alto (na metade norte) correspondendo às composições florísticas diferentes. As áreas mais férteis nas partes baixas da encosta (Martins 2010) coincidem com os perfis verticais mais altos, em alturas dominantes estão associadas com a qualidade de sítio (Jones, 1969).

As indicações de subdivisão da área a partir apenas do perfil vertical derivado do levantamento laser corresponderam aos padrões fitossociológicos levantados em estudos anteriores. Ressalta-se que as estimativas de altura derivadas do LiDAR aéreo são bastante precisas, ao contrário daquelas realizadas a partir do solo nos levantamentos convencionais, porém, o LiDAR sozinho não serve como indicativo de diferenças de composição florística entre ecosítios, apenas de estrutura vertical. O levantamento ALS prévio pode ser estratégico ao delineamento do esquema amostral in situ, servindo como ferramenta de planejamento, minimizando custos e otimizando as visitas a campo.

\section{CONCLUSÕES}

O levantamento ALS foi sensível na detecção de padrões de perfil vertical em escala de ecosítio ao longo de uma nuvem de pontos LiDAR originada de uma área de floresta ombrófila. Foram identificados quatro grupos com perfis verticais baixo, médio-baixo, médio-alto e alto ao longo da área estudada. A distribuição espacial dos grupos acompanhou a topografia, além de corresponder a diferenças de fitofisionomia encontradas por outros autores na região.

\section{AGRADECIMENTOS}

Este trabalho é parte do programa de pesquisa desenvolvido pelo GET-LiDAR (Grupo de Estudos em Tecnologia LiDAR). Agradecemos ao pesquisador Michael Keller, coordenador do programa Paisagens Sustentáveis, uma parceria da Embrapa Monitoramento por Satélite e do Serviço Florestal Americano (US-FS), por viabilizar e disponibilizar o levantamento laser aerotransportado. Agradecemos também à CAPES pelas bolsas de mestrado e doutorado concedidas aos pesquisadores envolvidos neste projeto. Agradecemos aos revisores anônimos, cujas contribuições ajudaram a melhorar este manuscrito.

\section{REFERÊNCIAS BIBLIOGRÁFICAS}

BROWN J. R.; K. S.; BROWN, G. G. Habitat alteration and species loss in Brazilian forests. In: WHITMORE, T. C.; SAYER, J. A. Tropical deforestation and species extinction. Londres: Chapman and Hall, 1992. p. 119-142. 
DEGRAAF, R. M.; MILLER, R. I. Conservation of faunal diversity in forested landscapes. Londres: Chapman and Hall, 1996. 634 p.

DRAKE, J. B.; KNOX, R. G.; DUBAYAH, R. O.; CLARK, D. B.; CONDIT, R.; BLAIR, J. B.; HOFTON, M. Aboveground biomass estimation in closed canopy Neotropical forests using lidar remote sensing: factors affecting the generality of relationships. Global Ecology and Biogeography, Oxford, v. 12, n. 2, p. 147-159, mar. 2003.

EISENLOHR, P. V.; MELO, M. M. R. F.; IVANAUSKAS, N. M.; SOUZA, V. C.; RODRIGUES, R. R.; DUARTE, A. R.; BREIER, T. B.; UDULUTSCH, R. G. Floresta Ombrófila Densa Atlântica: bases conceituais e estudo de caso no Parque Estadual Carlos Botelho, SP, Brasil. In: FELFILI, J. M.; EISENLOHR, P. V.; MELO, M. M. R. F.; ANDRADE, L. A.; MEIRA-NETO, J. A. A. Fitossociologia no Brasil: métodos e estudos de casos. Viçosa: Editora UFV, 2011. p. 372-387.

FELFILI, J. M.; EISENLOHR, P. V.; MELO, M. M. R. F;; ANDRADE, L. A.; MEIRA-NETO, J. A. A. Fitossociologia no Brasil: métodos e estudos de casos. Viçosa: Editora UFV, 2011.

GOMES, J. A. M. A.; BERNACCI, L. C.; JOLY, C. A. Diferenças florísticas e estruturais entre duas cotas altidudinais da Floresta Ombrófila Densa Submontana Attântica, do Parque Estadual da Serra do Mar, município de Ubatuba/SP , Brasil. Biota Neotropica, Campinas, v. 11, n. 2, p. 123-137, mai. 2011.

HILKER, T.; WULDER, M. A.; COOPS, N. C. Update of forest inventory data with lidar and high spatial resolution satellite imagery. Canadian Journal of Remote Sensing, Ottawa, v. 34, n. 1, p. 5-12, abr. 2008.

IF - INSTITUTO FLORESTAL DO ESTADO DE SÃO PAULO. Plano de manejo do Parque Estadual da Serra do Mar. 2006. Disponível em: <http://iflorestal.sp.gov.br/files/2013/03/Plano de Manejo Pe Serra do Mar. pdf>. Acesso em: 19 ago. 2014.

JOLY, C. A., LEITÃO FILHO, H. F.; SILVA, S. M. O patrimônio florístico. In: FUNDAÇÃO SOS MATA ATLÂNTICA. Mata Atlântica. Rio de Janeiro: Editora Index, 1991. p. 97-107.

JONES, J.R. Review and comparison of site evaluation methods. Fort Collins: USDA Forest Service, 1969. 27 p. (RM Research Paper, 51)

LACERDA, M. S. Composição florística e estrutura da comunidade arbórea num gradiente altitudinal da Mata Atlântica. 2001. 136 p. Tese (Doutorado em Biologia Vegetal) - Universidade Estadual de Campinas, Campinas, 2001.

LANA, J. M.; SOUZA, A. L.; MEIRA NETO, J. A. A.; SOARES, V. P.; FERNANDES FILHO, E. I. Análise dos estágios de sucessão de áreas de mata atlântica sob a influência de plantações florestais, Vale do Rio Doce, Minas Gerais, Brasil. Revista Árvore, Viçosa, v. 34, n. 4, p. 733-743, 2010.

LATHAM, P. A. ; ZUURING, H. R.; COBLE, D. W. A method for quantifying vertical forest structure. Forest Ecology and Management, Amsterdam, v. 104, n. 1-3, p. 157-170, mai. 1998.

MARTINS, S. C. Caracterização dos solos e serapilheira ao longo do gradiente altitudinal da Mata Atlântica, Estado de São Paulo. 2010. 155 p. Tese (Doutorado em Ciências) - Centro de Energia Nuclear na Agricultura. Universidade de São Paulo, Piracicaba, 2010.

MCROBERTS, R. E.; GOBAKKEN, T.; NÆSSET, E. Post-stratified estimation of forest area and growing stock volume using lidar-based stratification. Remote Sensing of Environment, New York, v. 125, p. 157-166, jul. 2012.

MEDEIROS, M. C. M. P. Caracterização fitofisionômica e estrutural de áreas de floresta ombrófila densa montana no Parque Estadual da Serra do Mar, SP, Brasil. 2009. 85 p. Dissertação (Mestrado em Biodiversidade Vegetal e Meio Ambiente) - Instituto de Botânica da Secretaria do Meio Ambiente, São Paulo, 2009.

Sci. For., Piracicaba, v. 43, n. 108, p. 873-884, dez. 2015 DOI: dx.doi.org/10.18671/scifor.v43n108.12 
Conto et al. - Caracterização do perfil vertical do dossel de um trecho

de Mata Atlântica através de escaneamento laser aerotransportado

MORSDORF, F.; MARELL, A.; KOETZ, B.; CASSAGNE, N.; PIMONT, F.; RIGOLOT, E.; ALLGOWER, B. Discrimination of vegetation strata in a multi-layered Mediterranean forest ecosystem using height and intensity information derived from airborne laser scanning. Remote Sensing of Environment, New York, v. 114, n. 7, p. 1403-1415, jul. 2010.

PASCUAL, C.; GARCÍA-ABRIL, A., GARCÍA-MONTERO, L. G., MARTÍN-FERNÁNDEZ, S., COHEN, W. B. Object-based semi-automatic approach for forest structure characterization using lidar data in heterogeneous Pinus sylvestris stands. Forest Ecology and Management, Amsterdam, v. 255, n. 11, p. 3677-3685, fev. 2008.

RIAÑO, D.; VALLADARES, F.; CONDÉS, S.; CHUVIECO, E. Estimation of leaf area index and covered ground from airborne laser scanner (Lidar) in two contrasting forests. Agricultural and Forest Meteorology, Amsterdam, v. 124, n. 3-4, p. 269-275, ago. 2004.

SILVA, A. G. P.; GÖRGENS, E. B.; CAMPOE, O. C.; ALVARES, C. A.; STAPE, J. L.; RODRIGUEZ, L. C. E. Assessing biomass based on canopy height profiles using airborne laser scanning data in eucalypt plantations. Scientia Agricola, v. 72, n. 6, p. 504-512, 2015.

TOMPPO, E.; OLSSON, H.; STAHL, G.; NILSSON, M.; HAGNER, O.; KATILA, M. Combining national forest inventory field plots and remote sensing data for forest databases. Remote Sensing of Environment, New York, v. 112, n. 5, p. 1982-1999, mai. 2008.

VELOSO, H. P.; RANGEL-FILHO, A. L. R.; LIMA, J. C. Classificação da vegetação brasileira adaptada a um sistema universal. Rio de Janeiro: IBGE, 1991. $124 \mathrm{p}$.

WHITE, J. C.; WULDER, M. A; VARHOLA, A.; VASTARANTA, M.; COOPS, N. C.; COOK, B. D.; PITT, D.; WOODS, M. A best practices guide for generating forest inventory attributes from airborne laser scanning data using an area-based approach. 2.ed. Victoria: Canadian Wood Fibre Centre, 2013. 39 p.

ZONETE, M. F.; RODRIGUEZ, L. C. E.; PACKALÉN, P. Estimação de parâmetros biométricos de plantios clonais de eucalipto no sul da Bahia: uma aplicação da tecnologia laser aerotransportada. Scientia Forestalis, Piracicaba, v. 38, n. 86, p. 225-235, jun. 2010.

Recebido em 20/08/2014

Aceito para publicação em 11/06/2015 